\title{
HOMOGENEOUS ENZYME-LINKED COMPETITIVE BINDING ASSAY FOR BIOTIN BASED ON THE AVIDIN-BIOTIN INTERACTION
}

\author{
SYLVIA DAUNERT and LEONIDAS G. BACHAS*
}

Department of Chemistry, University of Kentucky, Lexington, KY 40506-0055 (U.S.A.)

MARK E. MEYERHOFF

Department of Chemistry, University of Michigan, Ann Arbor, MI 48109-1055 (U.S.A.)

(Received 9th October 1987)

\section{SUMMARY}

A homogeneous enzyme-linked competitive-binding assay for biotin with glucose-6-phosphate dehydrogenase (G6PDH), is described. This assay is based on the interaction between a G6PDH/biotin conjugate with avidin, a natural binder for biotin. In the absence of biotin in the assay mixture, this interaction results in $100 \%$ inhibition of the enzyme conjugate. In the presence of biotin, the enzymatic activity of the conjugate is regained in an amount related to the concentration of the vitamin in the sample. Extremely steep, gate-like dose/response curves, attributable to the relative binding affinities of avidin for biotin and the conjugate, are observed. The detection limits of the system vary with the amounts of avidin and enzyme/biotin conjugate used. The method is rapid and sensitive and is evaluated for the direct determination of biotin in vitamin tablets.

Binding proteins are naturally occurring macromolecules that exhibit high affinity and selectivity for selected biomolecules. In certain instances, such proteins possess the properties required to be used in place of antibodies in a variety of modern enzyme-linked competitive binding assays. Indeed, the advantages of using endogenous binding proteins rather than antibodies in homogeneous enzyme-linked assay arrangements have been demonstrated recently [1,2]. The simple assays devised for folate [1] and vitamin $B_{12}$ [2] were rapid, selective, and exhibited unusually steep, gate-like dose/response behavior. This paper describes an analogous homogeneous competitive binding assay for biotin based on an enzyme/biotin conjugate and avidin, a natural biotin binder.

Biotin (vitamin $\mathrm{H}$ ) is an important coenzyme in enzymatic carboxylation reactions requiring ATP [3]. A deficiency of this vitamin results in anemia, dermatitis, desquamative erythroderma (Leiner's disease in children), and biotin-related inborn errors of metabolism [4]. Since its isolation in 1936 [5], 
several methods have been developed for the determination of biotin (for examples, see [6-14] ). Most of these conventional assays require separate extraction procedures and/or involve the use of costly equipment, reagents, etc.

More recently, three separate homogeneous enzyme-linked assays for biotin based on competitive binding with avidin have been proposed [15-17]; however, these methods offered only marginal detection capabilities. The new method described here offers at least a 50 -fold improvement in detection limits concomitant with much steeper dose/response curves. Further, it is demonstrated that it is feasible to prepare enzyme/ligand conjugates which can be inhibited up to $100 \%$ by low concentrations of the corresponding biological binder. This property combined with the intrinsic specificity and affinity of the avidin-biotin interaction results in a very fast, precise and selective method for detection of biotin. The analytical utility of the proposed assay procedure is demonstrated by determining biotin in commercial vitamin preparations.

\section{EXPERIMENTAL}

\section{Apparatus and reagents}

A Gilford Stasar-III spectrophotometer equipped with a vacuum-operated sampling system and a temperature-controlled cuvette (thermostated at $30^{\circ} \mathrm{C}$ throughout the experiments) was used in the determination of enzyme activities. This instrument was interfaced with a Syva CP-5000 EMIT clinical processor (set on delay and measurement times of $30 \mathrm{~s}$ ). A Syva pipetter/diluter (Model 1500) was used to deliver volumes of the conjugate, the standards, the binder, and the samples. Throughout this study, the pipetter/diluter was set so it could deliver a reagent volume of $50 \mu \mathrm{l}$ and dilute it with $100 \mu \mathrm{l}$ of assay buffer solution $(0.0500 \mathrm{M}$ Tris- $\mathrm{HCl}, 0.100 \mathrm{M} \mathrm{NaCl}, 0.010 \%(\mathrm{w} / \mathrm{v})$ sodium azide, $\mathrm{pH} 7.8$ ).

Gold-label dimethyl sulfoxide (DMSO) was purchased from Aldrich. Glucose-6-phosphate dehydrogenase (G6PDH) (from Leuconostoc mesenteroides $), d$-biotin- $N$-hydroxysuccinimide and all the other chemicals used were from Sigma Chemical Co. and were of the highest purity available. Tris/gelatin buffer ( $1.0 \%$ gelatin in assay buffer $)$ was used to prepare all the standards and to dilute the avidin, the enzyme, and the conjugates.

\section{Preparation of G6PDH/biotin conjugates}

The conjugates were prepared by reacting a quantity of G6PDH with different amounts of biotin- $N$-hydroxysuccinimide ester (dissolved in DMSO) $[1,18]$. The biotin ester solution $\left(2 \mathrm{mg} \mathrm{ml}^{-1}\right)$ was added in aliquots at 10 -min intervals into a solution of 200 units of enzyme, which was previously dialyzed in $0.100 \mathrm{M} \mathrm{NaHCO}_{3}, \mathrm{pH} 8.0$ buffer. The protein solution was kept at $4^{\circ} \mathrm{C}$ during the addition of the ester. The conjugation reaction was run for $130 \mathrm{~min}$ at $4{ }^{\circ} \mathrm{C}$ with stirring, while the active site of the enzyme was protected by add- 
ing an excess of glucose-6-phosphate and NADH compared to the amount of enzyme present [1]. Finally, the conjugate was dialyzed against the assay buffer solution and diluted to a final volume of $2 \mathrm{ml}$. The protein concentration corresponding to this conjugate preparation was $2.6 \mu \mathrm{M}$ (equivalent to 200 units of unmodified G6PDH). Variably substituted conjugates were prepared by using different mole ratios of activated biotin/G6PDH. The percentage of residual enzymatic activity of the conjugates was calculated by comparing the activities of conjugated enzyme to that of a solution containing unconjugated enzyme of the same protein concentration.

\section{Procedures}

Characterization of the conjugates. The enzymatic activity of the G6PDH conjugates was determined by measuring the rate of appearance of NADH at $340 \mathrm{~nm}$ with the spectrophotometer [1]. Measurements were taken after $30 \mathrm{~s}$ and $2 \mathrm{~min}$ and the enzymatic activity was calculated as the difference of these two absorbance values. When a $(1+1999)$ dilution of conjugate was used, the enzymatic activity was calculated as the net change in absorbance measured between $30 \mathrm{~s}$ and $10 \mathrm{~min}$.

The kinetics of the association between $50 \mu \mathrm{l}$ of a $(1+99)$ dilution of the $\mathrm{G} 6 \mathrm{PDH} /$ biotin conjugate and avidin were studied as described earlier [1]. Dilution curves for binding protein were used for further characterization of the conjugates. Using the pipeter/diluter, $50-\mu \mathrm{l}$ portions of solutions containing different concentrations of avidin in Tris-gelatin buffer were incubated with $50 \mu \mathrm{l}$ of a $(1+99)$ dilution of the G6PDH/biotin conjugate, and $50 \mu \mathrm{l}$ of Tris/ gelatin buffer. After $5 \mathrm{~min}$ of incubation at room temperature, the enzymatic activity of the reaction mixture was measured as above. A dilution curve for the binder was prepared by plotting percent inhibition vs. the amount of binder used.

Dose/response curves. A stock solution of biotin $(0.400 \mathrm{mM})$ was prepared by dissolving the corresponding amount of biotin in Tris/gelatin buffer. All the standards were made from dilutions of this stock solution with Tris/gelatin buffer. For the assay, $50 \mu \mathrm{l}$ of the standards, $50 \mu \mathrm{l}$ of a conjugate solution, and $50 \mu \mathrm{l}$ of an avidin solution were mixed and incubated at room temperature for 5 min in a single incubation mode [19]. The resulting enzymatic activity of the mixture was measured as above. A dose/response curve was prepared by plotting the percent inhibition vs. the logarithm of the concentration of the biotin in the standards.

Vitamin tablets. Five tablets (Biotin, Thompson, and Biotin, Perrigo) or ten tablets (Stress B-Complex, Bio-Genics) of each vitamin preparation were weighed and powdered [1]. An amount of the powder corresponding to one tablet (Biotin, Thompson, and Biotin, Perrigo) or two tablets (Stress B-Complex, Bio-Genics) was weighed and shaken vigorously with $5.00 \mathrm{ml}$ of $1.0 \mathrm{M}$ $\mathrm{NaOH}$ for $15 \mathrm{~min}$. The mixture was centrifuged at $2400 \mathrm{rpm}$ for $10 \mathrm{~min}$ and 
$4.00 \mathrm{ml}$ of the supernatant liquid was adjusted to a $\mathrm{pH}$ between 7 and 8 with hydrochloric acid. This preparation was then made to volume in a $25-\mathrm{ml}$ volumetric flask with Tris/gelatin buffer. Appropriate dilutions of the samples were prepared and processed by the procedure described above. For the recovery studies, a powdered amount of the Biotin preparation (Perrigo) corresponding to approximately $0.3 \mathrm{mg}$ of biotin (quantity of biotin per tablet claimed on the label by the manufacturer) was weighed and mixed with $745 \mu \mathrm{l}$ or 250 $\mu \mathrm{l}$ of a $0.100 \mathrm{mM}$ biotin solution. Then, $5.00 \mathrm{ml}$ of $1.0 \mathrm{M} \mathrm{NaOH}$ was added and the mixture was shaken for $15 \mathrm{~min}$. The rest of the procedure was the same as for the vitamin tablet. All incubations in both real-sample analysis and recovery studies were done at room temperature.

\section{RESULTS AND DISCUSSION}

An ideal conjugate for homogeneous enzyme-linked competitive binding assays should have high enzymatic activity and should be inhibited at or near $100 \%$ by an excess of binder. Further, ideal conjugates should also have as low a degree of ligand substitution (average number of ligands attached per enzyme molecule) as possible. The latter is necessary to obtain conjugates with favorable binding constants toward the respective binders. Indeed, for highly substituted conjugates, the statistical association constant between the binder and the conjugate is greatly increased [20] and this has been shown, theoretically, to result in assays with limited detection capabilities. The use of binding proteins instead of antibodies (which typically present bridging-group recognition problems [20]) counteracts to some extent this inherent limitation of homogeneous competitive binding assays as has been demonstrated theoretically (e.g., see Figs. 5 and 6 in [1]).

For the present study, several G6PDH/biotin conjugates were prepared with different mole ratios of biotin to enzyme. The various parameters characterizing the resulting conjugates are summarized in Table 1 . In the presence of excess of avidin, several of the conjugates could be inhibited $100 \%$ (i.e., zero enzymatic activity). From Table 1, it can also be seen that increasing the initial molar ratio of biotin to enzyme results in a higher degree of conjugation as evidenced by the lower residual activities of the conjugates. Based on previous data $[1,2]$, a comparison between conjugates of $\mathrm{G} 6 \mathrm{PDH}$ with biotin, folate and vitamin $B_{12}$ is shown in Table 2 . While all conjugates were prepared by using similar reaction conditions $[1,2]$, it is clear that the biotin system yields conjugates with the highest inhibition for the same initial mole ratio of ligand to enzyme. The conjugate prepared with a 100:1 mole ratio of biotin to enzyme, $\mathrm{BC}-1$, which had a maximum inhibition of $98 \%$ was used in all subsequent experiments.

It is known that in order for avidin to bind biotin, the carboxylic group of the latter has to be at least $9 \AA$ from the surface of the protein (i.e., biotin is 
TABLE 1

Parameters of G6PDH/biotin conjugates

\begin{tabular}{lccc}
\hline Conjugate & $\begin{array}{l}\text { Initial ratio } \\
\text { biotin/G6PDH }\end{array}$ & $\begin{array}{l}\text { Residual } \\
\text { activity } \\
(\%)\end{array}$ & $\begin{array}{l}\text { Inhibition }^{\text {a }} \\
(\%)\end{array}$ \\
\hline BC-1 & 100 & 26 & 98 \\
BC-2 & 200 & 11 & 100 \\
BC-3 & 500 & 4.8 & 100 \\
BC-4 & 1000 & 1.2 & 100 \\
\hline
\end{tabular}

aTo determine the \% inhibition, an excess of avidin was used with $(1+99)$ dilutions of $\mathrm{BC}-1$ and $\mathrm{BC}-2$, and $(1+19)$ dilutions of $\mathrm{BC}-3$ and BC-4. The conjugates and the avidin were incubated for 5 min before the enzymatic activity was measured.

essentially buried within the binding site of avidin ) [21,22]. However, the link provided by the lysine residue in biotinylated G6PDH allows only for $7.1 \AA$ between the carboxylic group of biotin and the polypeptide chain. Therefore, we believe that in the case of enzyme/biotin conjugates, formation of the avidin-biotin complex will bring the avidin right on the surface of the conjugate resulting in $100 \%$ inhibition.

The effect of changing the reaction time between avidin and the conjugate BC-1 was studied (association kinetics study) (Fig. 1). Extremely small quantities of avidin in the assay, $125 \mathrm{ng}\left(50 \mu \mathrm{l}\right.$ of $2.5 \mu \mathrm{g} \mathrm{ml}^{-1}$ solution of avidin) and $62.5 \mathrm{ng}\left(50 \mu \mathrm{l}\right.$ of $1.25 \mu \mathrm{g} \mathrm{ml}^{-1}$ solution of avidin), were capable of inhibiting the enzyme conjugate up to $87 \%$ and $58 \%$, respectively, after a 40 -min reaction period. However, within $5 \mathrm{~min}, 93 \%$ and $89 \%$ of the maximum inhibition was observed, respectively. Thus, to increase the speed of the biotin assays, a 5min incubation time period was chosen for the remaining studies. It should be

TABLE 2

Comparison of G6PDH/ligand conjugates

\begin{tabular}{llll}
\hline $\begin{array}{l}\text { Initial ratio } \\
\text { (ligand/G6PDH) }\end{array}$ & \multicolumn{2}{l}{ Inhibition (\%) } & \\
\cline { 2 - 4 } & G6PDH/biotin & G6PDH/vitamin B & G6PDH/folate \\
\hline 100 & 98 & 19 & \\
200 & 100 & 46 & 21 \\
300 & & 65 & 36 \\
400 & 100 & 77 & 70 \\
500 & & & \\
800 & 100 & & \\
1000 & & & \\
\hline
\end{tabular}

The conjugation reactions were carried out under similar conditions. 

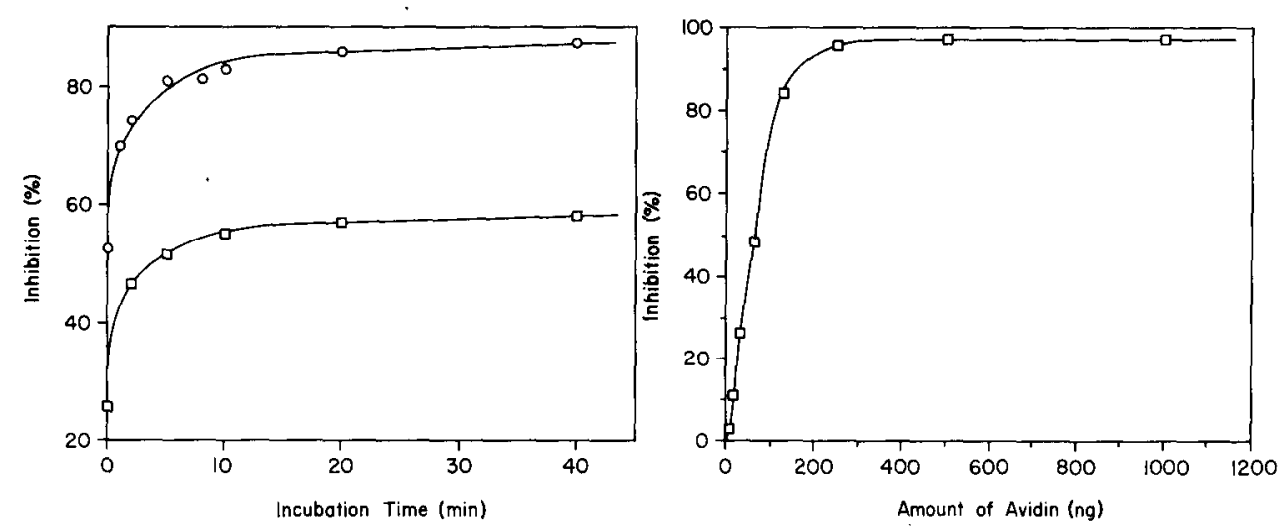

Fig. 1. Association curve for a $(1+99)$ dilution of BC-1 with two dilutions of avidin: (O) $2.5 \mu \mathrm{g}$ $\mathrm{ml}^{-1}$ avidin; ( $\square$ ) $1.25 \mu \mathrm{g} \mathrm{ml}^{-1}$ avidin. The incubation time was varied from zero (minimum time required to mix the reagents and measure the enzymatic activity) to $40 \mathrm{~min}$. Data points are means of duplicate measurements.

Fig. 2. Effect of varying the levels of avidin (ng of avidin in assay mixture) on the inhibition of a $(1+99)$ dilution of $\mathrm{BC}-1$. Values shown are means of duplicate measurements.

noted that conjugate $\mathrm{BC}-3$ exhibited $100 \%$ inhibition even when the incubation time approached zero (i.e., measuring the enzymatic activity right after mixing the reagents). To our knowledge, this is the first time that, even without any incubation, such a high inhibition has been observed in this type of homogeneous assay.

When compared with the association curves previously obtained using a $\mathrm{G} 6 \mathrm{PDH} /$ folate conjugate with folate-binding protein [1] and a $\mathrm{G} 6 \mathrm{PDH} /$ vitamin $\mathrm{B}_{12}$ conjugate with R-protein [2], the curves of Fig. 1 indicate a much faster association between $\mathrm{BC}-1$ and avidin as indicated by the initial slope of the association curve. This can be partly explained by the expected relatively high value for the association rate constant between the $\mathrm{G} 6 \mathrm{PDH} /$ biotin and avidin. Indeed, the rate constant for the interaction of biotin and avidin has been estimated at $7 \times 10^{7} \mathrm{M}^{-1} \mathrm{~s}^{-1}$ [22]. For comparison, a value of $10^{8} \mathrm{M}^{-1} \mathrm{~s}^{-1}$ is the proposed diffusion-controlled limit for this rate constant if the electrostatic repulsion between the ligand and the binder are taken into account [23].

For the binder-dilution studies, different amounts of avidin were incubated for 5 min with the same amount of conjugate $(50 \mu \mathrm{l}$ of a $(1+99)$ dilution of BC-1). As shown in Fig. 2, the more avidin in the assay, the more the conjugate is inhibited by the binder. This conjugate was $97 \%$ inhibited when incubated for 5 min with $500 \mathrm{ng}$ of avidin ( $50 \mu \mathrm{l}$ of a $10.0 \mu \mathrm{g} \mathrm{ml}^{-1}$ avidin solution).

A typical dose/response curve obtained by using a $14.3 \mu \mathrm{g} \mathrm{ml}^{-1}$ avidin solution and a $(1+99)$ dilution of BC-1 is shown in Fig. 3. The solid line corre- 

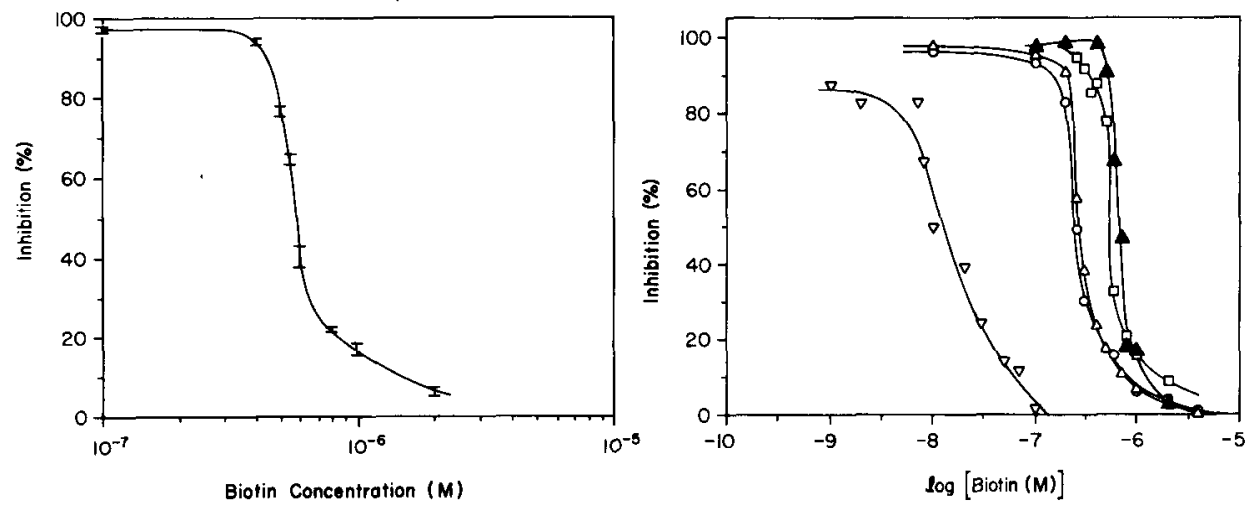

Fig. 3. Typical dose/response curve for biotin. Error bars are \pm 1 s.d. $(n=5)$. Conditions: $(1+99)$ dilution of $\mathrm{BC}-1$ and $14.3 \mu \mathrm{g} \mathrm{ml}^{-1}$ avidin solution. The $x$-axis refers to concentrations of biotin in the standards.

Fig. 4. Effects of various conjugate and avidin concentrations on the dose/response curve. Means of duplicate measurements were plotted. The reagent concentrations used were as follows: $(\nabla)$ $0.714 \mu \mathrm{g} \mathrm{ml}^{-1}$ avidin, $(1+1999)$ dilution $\mathrm{BC}-1$; (O) $7.14 \mu \mathrm{g} \mathrm{ml}^{-1}$ avidin, $(1+99)$ dilution $\mathrm{BC}-1$; ( $\triangle$ ) $7.14 \mu \mathrm{g} \mathrm{ml}^{-1}$ avidin, (1+199) dilution BC-1; ( $\left.\square\right) 14.3 \mu \mathrm{g} \mathrm{ml}^{-1}$ avidin, (1+99) dilution BC1; (A) $14.3 \mu \mathrm{g} \mathrm{ml}^{-1}$ avidin, $(1+199)$ dilution BC-1. Biotin concentration refer to the standards used.

sponds to the average inhibition for five separate measurements. The reproducibility of this method is demonstrated by the error bars ( \pm 1 s.d.). The standard deviation for each biotin concentration was calculated as described previously [1]. As shown, the curve is extremely steep over a very narrow concentration range. Indeed, $77 \%$ inhibition was observed at $0.500 \mu \mathrm{M}$ biotin concentration in the standard, while the conjugate is inhibited by only $21 \%$ when the biotin concentration in the standard was increased to just 0.800 $\mu \mathrm{M}$. As expected, the standard deviation (with respect to inhibition) is higher at the steep portion of the dose/response curve and more or less constant over the remainder of the curve. As suggested by Rodbard [24], this type of curve may be useful in calculating an approximate percent error corresponding to a dose estimate. For example, according to Fig. 3 , an inhibition of $50 \%$ will correspond to a biotin concentration of $0.578 \mu \mathrm{M}$ with an associated relative error of $\pm 2.2 \%$ (estimated as suggested in [24]).

The effect of varying the concentration of avidin and conjugate on the performance of the assays was evaluated. The results, summarized in Fig. 4, indicate that the $\mathrm{ED}_{50}$ value of the dose/response curve is greatly dependent on the amount of avidin present. Thus, the $\mathrm{ED}_{50}$ is shifted by approximately half when the concentration of avidin in the assay mixture is halved. Similarly, reducing the concentration of avidin ten-fold was also observed to decrease the $\mathrm{ED}_{50}$ value by approximately an order of magnitude. In general, the greater the concentration of binder in the assay, the steeper the dose/response curve, the 
greater the maximum inhibition, and the poorer the $\mathrm{ED}_{50}$ values. When more dilute solutions of avidin and biotin/G6PDH were used, an improvement of detection limits was observed at the expense of a decrease in the steepness of the dose/response curve.

By using a $0.714 \mu \mathrm{g} \mathrm{ml}^{-1}$ solution of avidin and a $(1+1999)$ dilution of BC1 , concentrations of biotin down to $8 \mathrm{nM}$ (concentration of biotin in the sample) which corresponds to $1 \mathrm{pg}$ of biotin, could be determined. The concentration of biotin in the assay mixture is one ninth of the latter which corresponds to a detection limit of approximately $0.9 \mathrm{nM}$ biotin in the assay. This is a 50 -, 110 - and 500 -fold improvement over the detection limits reported by Niedbala et al. [17], Gebauer and Rechnitz [15], and Ngo et al. [16], respectively. Further, the sensitivity (steepness of the dose/response curve) of the previous biotin assays is inferior by at least an order of magnitude when compared to that reported here [15-17]. Even better detection limits may be obtained with this new assay by using even lower concentrations of reagents. The latter, however, will be at the expense of an increase in the time needed for the overall assay.

The improved detection limits that were observed here, compared to the ones reported earlier $[15,16]$, can be explained by the fact that in the present experiments, the conjugation of the enzyme was done in the presence of G6P and $\mathrm{NADH}$ in order to protect the active site of the enzyme. Therefore, the conjugates lose less activity during conjugation which leads to assays with increased sensitivity. Further, compared to the work of Niedbala et al. [17], the present lower detection limits can be attributed to the fact that the conjugate preparation shows higher inhibition in the presence of a smaller amount of avidin. Specifically, the conjugate $\mathrm{BC}-1$ was inhibited more than $80 \%$ in the assay with $36 \mathrm{ng}$ of avidin, whereas in the earlier assay [17] an amount of 500 ng of avidin was needed to achieve $70 \%$ inhibition (in both assays the concentration of conjugate was approximately the same).

Figure 4 also indicates that when either a $14.3 \mu \mathrm{g} \mathrm{ml}^{-1}$ or a $7.14 \mu \mathrm{g} \mathrm{ml}^{-1}$ solution of avidin was used, the $\mathrm{ED}_{50}$ value (effective dose at $50 \%$ of maximum response) was virtually independent on whether a $(1+99)$ or $(1+199)$ dilution of $\mathrm{BC}-1$ was used. These observations agree well with previous theoretical predictions for such enzyme-linked assay systems [20]. Indeed, from earlier work (Fig. 5 in [20]), it can be inferred that when the concentration of binder is much higher than the concentration of conjugate (as is the case in the assay described here) changes in the concentration of the latter do not affect the $\mathrm{ED}_{50}$ value substantially. The same theoretical model also predicts extremely steep dose/response behavior whenever the binder associates more strongly with the analyte than the enzyme-labeled ligand [1]. This is likely to occur when natural binding proteins such as avidin are used.

The long-term stability of the dose/response curves was evaluated by comparing their $\mathrm{ED}_{50}$ values over a 35 -day period for a given binder $\left(14.3 \mu \mathrm{g} \mathrm{ml}^{-1}\right)$ 
TABLE 3

Results for selected vitamin tablets

\begin{tabular}{lcccccc}
\hline Vitamin tablet & \multicolumn{2}{l}{$\begin{array}{l}\text { Amount of biotin per } \\
\text { tablet }(\mu \mathrm{g})\end{array}$} & & \multicolumn{2}{l}{ Recovery study } \\
\cline { 2 - 3 } \cline { 5 - 6 } & Found $^{\mathrm{a}}$ & Claimed & & $\begin{array}{l}\text { Added } \\
(\mu \mathrm{g})\end{array}$ & $\begin{array}{l}\text { Found } \\
(\mu \mathrm{g})\end{array}$ & $\begin{array}{l}\text { Recovery } \\
(\%)\end{array}$ \\
\hline Stress B Complex $^{\mathrm{b}}$ & 12.5 & 12.5 & - & - & - \\
Biotin $^{\mathrm{c}}$ & 150 & 150 & - & - & - \\
Biotin $^{\mathrm{d}}$ & 291 & 300 & 73.3 & 76.2 & 104 \\
& & & 147 & 149 & 101 \\
\hline
\end{tabular}

${ }^{a}$ Average of two determinations. ${ }^{b}$ Bio-Genics, Canoga Park, CA; these tablets also contained vitamins $\mathrm{B}_{1}, \mathrm{~B}_{2}, \mathrm{~B}_{6}\left(5 \mathrm{mg}\right.$ each) and $\mathrm{B}_{12}(12.5 \mu \mathrm{g})$ with niacin, calcium $d$-pantothenate, choline bitartrate and inositol (50 mg each), folic acid $(0.2 \mathrm{mg})$, vitamin $\mathrm{C}(75 \mathrm{mg})$ and $p$-aminobenzoic acid (15 mg). ${ }^{~} \mathrm{Wm}$.T. Thompson Co., Carson, CA. ${ }^{\mathrm{T}}$ Perrigo, Allegan, MI.

and conjugate concentration $\left(1+99\right.$ dilution). The $\mathrm{ED}_{50}$ value of a typical dose/response curve fell within the range of $0.566 \mu \mathrm{M}$ to $0.578 \mu \mathrm{M}$ (for three random observations).

To demonstrate the feasibility of using this new assay for real samples, the determination of biotin in three different commercial vitamin preparations was undertaken. Table 3 summarizes the results of the assays. The amounts of biotin found were within $3 \%$ of the amount claimed by the manufacturers. The data for the multivitamin tablet also demonstrate the high selectivity of the assay in practical situations. The results of the recovery study are also shown in Table 3; the excellent recoveries suggest the absence of matrix effects.

In conclusion, the assay can detect as little as $8 \mathrm{nM}$ biotin in samples (or equivalently, $1 \mathrm{pg}$ of biotin in the assay) which is orders of magnitude better than the existing homogeneous competitive binding methods. Because of the extreme steepness of the dose/response curves, this assay method may find applications in quality control situations, where a decision on whether or not a product has a biotin content higher than a minimum cutoff level has to be made.

This work was supported by the Singletary Fund for Excellence, University of Kentucky (L.G.B.) and the National Science Foundation (CHE-8506695) (M.E.M.).

\section{REFERENCES}

1 L.G. Bachas and M.E. Meyerhoff, Anal. Chem., 58 (1986) 956.

2 C.D. Tsalta and M.E. Meyerhoff, Anal. Chem., 59 (1987) 837. 
3 R.S. Harris, P. György and B.W. Langer, in W.H. Sebrell, Jr. and R.S. Harris (Eds.), The Vitamins, Vol. II, Academic, New York, 1968, p. 261.

4 M.M. Mock and B.D. DuBois, Anal. Biochem., 153 (1986) 272.

5 F. Kögl and B. Tönnis, Z. Physiol. Chem., 242 (1936) 43.

6 E.E. Snell, in P. György (Ed.), Vitamin Methods, Vol. I, Academic, New York, 1950, p. 328.

7 N.M. Green, Biochem. J., 94 (1965) 23c.

8 V. Viswanathan, F.P. Mahn, V.S. Venturella and B.Z. Senkowski, J. Pharm. Sci., 59 (1970) 400.

9 T. Horsburgh and D. Gompertz, Clin. Chim. Acta, 82 (1978) 215.

10 R.D. Nargessi and D.S. Smith, Methods Enzymol., 62 (1979) 67.

11 R.L. Hood, Methods Enzymol., 62 (1979) 279.

12 K. Dakshinamurti and L. Allan, Methods Enzymol., 62 (1979) 284.

13 M.H.H. Al-Hakiem, J. Landon, D.S. Smith and R.D. Nargessi, Anal. Biochem., 116 (1981) 264.

14 E. Röder, U. Engelbert and J. Troschütz, Fresenius' Z. Anal. Chem., 319 (1984) 426.

15 C.R. Gebauer and G.A. Rechnitz, Anal. Biochem., 103 (1980) 280.

16 T.T. Ngo, H.M. Lenhoff and J. Ivy, Appl. Biochem. Biotechnol., 7 (1982) 443.

17 R. Niedbala, F. Gergits, III and K.J. Schray, J. Biochem. Biophys. Methods, 13 (1986) 205.

18 L.G. Bachas, P.F. Lewis and M.E. Meyerhoff, Anal. Chem., 56 (1984) 1723.

19 A. Zettner, Clin. Chem. (Winston-Salem, N.C.), 19 (1973) 699.

20 L.G. Bachas and M.E. Meyerhoff, Anal. Biochem., 156 (1986) 223.

21 N.M. Green, L. Konieczny, E.J. Toms and R.C. Valentine, Biochem. J., 125 (1971) 785.

22 N.M. Green, Adv. Protein Chem., 29 (1975) 84.

23 A. Froese and A.H. Sehon, Immunochemistry, 2 (1965) 135.

24 D. Rodbard, in J. Langan and J.J. Clapp (Eds.), Ligand Assay, Masson Publishing, New York, 1981, p. 45. 